\title{
A transnacionalidade e a proteção jurídica dos conhecimentos tradicionais na Bolívia, Colômbia, Equador, Guianas, Peru, Suriname e Venezuela
}

\author{
Transnationality and legal protection of traditional knowledge in \\ Bolivia, Colombia, Ecuador, Guianas, Peru, Suriname and Venezuela
}

\author{
Ana Carolina Couto Matheus \\ Universidade Federal do Acre - UFAC
}

Resumo O objeto do trabalho é estudar a transnacionalidade e a proteção jurídica dos conhecimentos tradicionais na Bolívia, na Colômbia, no Equador, nas Guianas, no Peru, no Suriname e na Venezuela, países que integram a região amazônica. Comporta necessariamente um tratamento transdisciplinar, pois as categorias de construções da realidade são diversas, e, embora diferentes, encontram-se profundamente interligadas ou interdependentes. O método utilizado na fase de investigação e na fase de tratamento dos dados foi o indutivo. Nas diversas fases da pesquisa foram acionadas as técnicas do referente, da categoria, do conceito operacional, da pesquisa bibliográfica e do fichamento. O desenvolvimento do tema pautou-se pela persecução dos objetivos geral e específicos que nortearam a produção. $\mathrm{O}$ relatório se encerra com as considerações finais e consubstancia o resultado de todos os achados da pesquisa, findando por confirmar a hipótese inicialmente concebida. Palavras-chave: Conhecimentos Tradicionais Associados à Biodiversidade. Região Amazônica. Proteção Jurídica. Sustentabilidade.

\begin{abstract}
The object of this work is to study the transnationality and legal protection of traditional knowledge in Bolivia, Colombia, Ecuador, Guyana, Peru, Suriname and Venezuela, countries that make up the Amazon region. It necessarily entails transdisciplinary treatment, since the categories of constructions of reality are diverse, and although different, they are deeply interconnected or interdependent. The method used in the research phase and in the data processing phase was inductive. In the various phases of the research the techniques of referent, category, operational concept, bibliographic research and file were used. The development of the theme was guided by the pursuit of the general and specific objectives that guided the production. The report concludes with the conclusions and substantiates the results of all research findings, eventually confirming the hypothesis initially conceived.
\end{abstract}

Keywords: Traditional Knowledge Associated with Biodiversity. Amazon region. LEGAL protection. Sustainability. 


\section{INTRODUÇÃO}

Considerando a imprescindível inter-relação dos conhecimentos tradicionais dos povos da Amazônia com a sustentabilidade, o objeto basilar do presente trabalho é compreender a realidade jurídica dos conhecimentos tradicionais associados à biodiversidade amazônica na Bolívia, na Colômbia, no Equador, nas Guianas, no Peru, no Suriname e na Venezuela, países que integram a região amazônica.

A escolha do tema justifica-se em razão da importância e complexidade. Comporta necessariamente um tratamento transdisciplinar, uma vez que as categorias de construções da realidade são diversas, e, embora diferentes, encontram-se profundamente interligadas ou interdependentes.

Assim posto, o problema da pesquisa em testilha é evidenciar a proteção jurídica dos conhecimentos tradicionais nos países que integram a região amazônica, tendo em vista a amplitude do tema e a necessidade de melhorar a proteção jurídica desses importantes conhecimentos geracionais. $\mathrm{O}$ aludido problema concentra seus esforços na busca de substituir o sistema de patentes, bem como, o sistema de garantia dos direitos de autor, inadequados para proteger as comunidades tradicionais.

Todo trabalho encontra-se parametrizado teoricamente na Constituição Federal de 1988, na legislação nacional e estrangeira, em vasta literatura nacional e estrangeira, artigos de revistas jurídicas especializadas e jurisprudência pertinente ao tema.

Para o equacionamento do problema, suscita-se a seguinte hipótese, a saber: a floresta amazônica está inserida além do Brasil, em territórios de outros países sul-americanos, como a Bolívia, a Colômbia, o Equador, as Guianas, o Peru, o Suriname e a Venezuela, portanto, sua conservação exige, necessariamente, o compromisso e a organização de todos esses países. $\mathrm{O}$ trabalho investiga juridicamente se existe a possibilidade de, neste cenário transnacional, exercer-se a tutela sustentável dos conhecimentos tradicionais associados à biodiversidade amazônica por meio da proteção jurídica.

Em função da problemática e da hipótese, o objetivo geral do trabalho consiste em analisar a proteção jurídica dos conhecimentos tradicionais associados à biodiversidade nos países que integram a região amazônica, considerando a imprescindível inter-relação dos conhecimentos tradicionais dos povos da Amazônia com a conservação ambiental.

A hipótese retromencionada impulsionou o desenho dos seguintes objetivos específicos para se alcançar os achados pretendidos: estudar o conceito, o paradigma, as características e noções gerais da transnacionalidade; verificar no ordenamento vigente o arcabouço jurídico aplicado aos conhecimentos tradicionais dos povos da Amazônia na Bolívia, na Colômbia, no Equador, nas Guianas, no Peru, no Suriname e na Venezuela, países que integram a região amazônica; enfatizar a limitada proteção que oferecem os direitos nacionais e a tutela internacional em vigor relacionada aos conhecimentos tradicionais associados à biodiversidade amazônica, considerando sua imprescindível inter-relação com a sustentabilidade.

O marco de referência privilegia a construção teórica segundo a qual estuda a proteção jurídica dos conhecimentos tradicionais associados à biodiversidade nos países que integram a região amazônica e se desdobra por meio de três pontos principais: o primeiro estuda a transnacionalidade; o segundo enfatiza a legislação aplicada aos conhecimentos 
tradicionais nos países que integram a região amazônica, exceto o Brasil; a limitada proteção que oferecem os direitos nacionais e a tutela internacional; e o terceiro verifica o tratamento sustentável dos conhecimentos tradicionais associados à biodiversidade amazônica.

Pelo método de abordagem indutivo, fonte de pesquisa bibliográfica e legal relativa aos conhecimentos tradicionais associados à biodiversidade amazônica serão pesquisadas e confrontadas as partes de um todo para que se possa ter uma visão generalizada. Durante as diversas fases da pesquisa serão utilizadas as técnicas do referente, da categoria, do conceito operacional, do fichamento e com base em documentação indireta será realizada a pesquisa bibliográfica.

O trabalho em apreço finda com as conclusões, em que serão apresentados pontos conclusivos abstraídos da pesquisa, a análise e a inferência das reflexões realizadas em relação à proteção jurídica e ao tratamento sustentável dos conhecimentos tradicionais associados à biodiversidade nos países que integram a região amazônica.

\section{O ESTUDO DA TRANSNACIONALIDADE}

Insta consignar, preliminarmente, que não se pretende aqui compilar estudo de natureza fundamentalmente histórica acerca do instituto, menos ainda desvendar todas as tônicas que envolvem o tema, já que este não é o objeto do presente trabalho. A temática aqui trabalhada tem o escopo de perfilar o conceito, o paradigma, as características e noções gerais que possam levar ao encontro dos objetivos específicos traçados para este estudo.

Para Ferrajoli (1999, p. 125), "soberania é o conceito, ao mesmo tempo político e jurídico, em que confluem todos os problemas e contradições da teoria positivista do Direito e do Estado Constitucional Moderno". A partir de 1970, a globalização enfraqueceu a soberania dos Estados nacionais.

Em relação às limitações impostas à soberania, Silva (2011, p. 260) explica que, no século XX, ocorreu um processo de geração de um regime internacional liberal de soberania. Isso significa que a soberania é limitada por um conjunto de aspectos em que o Estado soberano deve obediência e respeito. O capitalismo transnacional dita regras para os Estados nacionais.

\footnotetext{
The globalization of capitalism with its destabilizing effects in less industrialized countries, the technological revolution in transportation and communication, global political transformations as decolonization and the universalization of human rights and the expansion of social networks that facilitate reproduction transnational migration, economic and political organization (FERRAJOLI, 1999, p. 125).
}

A transnacionalidade não se trata de um fenômeno novo, supõe o amadurecimento do sistema de Estados-nações, um acontecimento do século XX, que alcançou sua plenitude após a Segunda Guerra Mundial, com o processo de descolonização e os avanços tecnológicos nas indústrias de comunicação e transportes. Entre os processos históricos que redundaram na nova ordem mundial, destaca-se a expansão do capitalismo em âmbito planetário.

No atual contexto socioeconômico mundial, os Estados continuam a exercer soberanamente sua autoridade nos limites de seu território. Muitos já não conseguem estabelecer 
e realizar seus objetivos, estão limitados em autonomia e sua economia depende da globalizada. Dependem de investimentos e tecnologias estrangeiros. Elegem seus governantes, mas não escolhem sua política econômica.

O Estado não consegue mais responder aos inúmeros problemas sociais diante da complexidade das demandas transnacionais. A crescente globalização dos mercados prejudica a autonomia e a capacidade de ação político-econômica dos Estados. A ideia de um Estado Transnacional, como concebida por Beck (2002, p. 12), torna-se uma das alternativas possíveis, embora o Estado Constitucional Moderno continue "importante como espaço público garantidor das políticas internas e externas” (CRUZ e BODNAR, 2009, p. 18).

O Direito Internacional não consegue gerar mecanismos eficazes de governança, regulação, intervenção e coerção para as demandas transnacionais. O Direito Comunitário não apresenta bases teóricas suficientes para a caracterização de um ou mais espaços públicos transnacionais. Cruz e Bodnar propõem:

A criação de espaços públicos que possam perpassar estados nacionais. (...) O Estado e o Direito Transnacional poderiam ser propostos a partir de um ou mais espaços públicos transnacionais. (...) O Estado Constitucional Moderno, construído teoricamente para existir soberano no seu interior e para se relacionar conflitivamente com o seu exterior, deve sair de cena, substituído por um novo modelo de Estado que, ao que tudo indica, será o mediador das relações políticas, sociais e econômicas locais e regionais com aquelas globalizadas, ou mundializadas. É importante registrar que, para construir o novo Estado Transnacional a partir da Democracia, é preciso superar a pressuposição amedrontadora, mas falsa, de que adversidade aumentada traz automaticamente a tensão e o conflito social. Pode ser exatamente o contrário. O conflito na Sociedade não é apenas necessário, ele é desejável. Providenciados os arranjos sociais adequados, a variedade pode contribuir para uma civilização segura e estável, ao contrário da proposta endógena que orientou o Estado Constitucional Moderno até agora (CRUZ e BODNAR, 2009, p. 2-4).

O Estado vem, progressivamente, perdendo o domínio sobre a produção, e, por conseguinte, de receitas a serem tributadas, que interferem diretamente em seu equilíbrio, uma vez que a demanda financeira do Estado é suprida por uma captação de impostos gerida de forma privada. Uma das evidências do enfraquecimento da soberania interna dos Estados é a falta de controle das classes compostas por pessoas marginalizadas, haja vista o crescimento da indústria de segurança interna e a necessidade de construções de penitenciárias para conter as revoltas desses grupos.

O esvaziamento da soberania do Estado, em face de problemas que não se podem ser resolvidos no âmbito dos Estados nacionais, nem por acordo entre Estados soberanos, no tocante às questões ambientais, urge reestruturação e ampliação das capacidades de ação política, em plano supranacional, como já existe na Europa, na América do Norte e na Ásia.

Portanto, evidencia-se o fenômeno da transnacionalidade, principalmente quando relacionado às questões ambientais. Em relação à construção do conceito de transnacionalidade, Jessup (1956, p. 1) propôs a "lei transnacional" e a definiu "to include all law which regulates actions or events that transcend national frontiers. Both public and private international law are included, as are other rules which do not wholly fit into such standard 
categories". Foi um grande defensor do conceito de Direito Transnacional e escreveu que o Direito Internacional Público não poderia ser eficaz sem "tolerância de certas diferenças decorrentes de vários sistemas jurídicos” (JESSUP, 1963, p. 2). Koh desenvolveu o "Transnational Legal Process" que:

\footnotetext{
Describe the theory and pratices of how public and private actors - nations-states, international organizations, multinational enterprises, non-governmental organizations, and private individuals - interact in a variety of public and private, domestic and international for a to make, interpret, enforce, and ultimately, internalize rules of transnational law (KOH, 1996, p. 206-207).
}

Cruz e Bodnar (2009, p. 6) propõem que "o prefixo trans indique que a estrutura pública transnacional poderia perpassar vários Estados". Advertem que "não se está falando de estado mundial ou de um superestado", mas sim "a possibilidade de fundação de vários espaços públicos de governança, regulação e intervenção, cujos mecanismos de controle e funcionamento seriam submetidos às sociedades transnacionalizadas". Ferrer (2002, p. 21) explica que não se trata de se estabelecer uma república planetária, mas sim da busca de mecanismos institucionais que assegurem solidariedade e inspirem novos direitos transnacionais, como é o caso do direito ambiental.

A Rio-92 foi a maior conferência mundial sobre meio ambiente realizada para tratar da proteção do meio ambiente e desenvolvimento sustentável. Nessa conferência, foram aprovados os princípios e diretrizes a serem observados em escala global. Ressalta-se a importância do paradigma da transnacionalidade. Paradigma é sinônimo de verdade, para Khun (2000, p. 142) é o modelo que os membros de uma comunidade compartilham, e segue uma matriz composta por generalizações simbólicas, crenças em determinados modelos heurísticos e valores exemplares.

Estado Transnacional é a "emergência de novos espaços públicos plurais, solidários e cooperativamente democráticos e livres das amarras ideológicas da modernidade, decorrentes da intensificação da complexidade das relações globais, dotados de capacidade jurídica de governança, regulação, intervenção" (CRUZ e BODNAR, 2009, p. 6) para projetar a construção de um novo pacto de civilização.

\section{A transnacionalidade E a PROTEÇÃo JURídica dos CONHECIMENTOS TRADICIONAIS ASSOCIADOS À BIODIVERSIDADE AMAZÔNICA}

Em Cruz e Bodnar (2009, p. 4), a questão vital ambiental justifica a construção de espaços públicos transnacionais, com a instituição de um Direito Transnacional que transpassaria vários Estados nacionais, com capacidade própria de aplicação coercitiva por uma estrutura organizativa transnacional. Agregaria a mesma lógica do Estado Constitucional Moderno, formado a partir de normas jurídicas inter-relacionadas formadoras de um sistema.

Para Cruz e Bodnar (2009, p. 16), o ordenamento jurídico transnacional apresentaria características próprias, derivadas da mesma concepção do Estado Transnacional como organização destinada a atuar em espaço de governança regulatória e de intervenção até agora não organizado politicamente. 
O Direito Transnacional e o Estado Transnacional diferem do Estado Constitucional Moderno. Quanto à soberania exercida pelos Estados nacionais e se encontra em estado de obsolescência, a cidadania necessitaria ser exercida em outras bases, em que se privilegiariam a solidariedade e a cooperação entre pessoas, instituição e Estados, em busca da proteção de bens e valores imprescindíveis, assegurando a vida.

Em relação à territorialidade, o Direito Transnacional e o Estado Transnacional estariam "desterritorializado", não é o espaço estatal nacional, nem o espaço que está acima dele. "Está por entre eles, ou seja, desvinculado da delimitação precisa do âmbito territorial em que o Estado Constitucional Moderno tenta exercer soberania e tenta impor coercitivamente as suas leis" (CRUZ e BODNAR, 2009, p. 15).

O Estado Transnacional seria a superação do Estado Constitucional Moderno, libertando-o da armadilha territorial e soberania. Reconheceria a globalidade e preconizaria a organização do Direito Transnacional pela redefinição e revitalização do político como Estado e como sociedade. É utópica a ideia de uma nova ordem mundial, porém algumas instituições internacionais já exercem suas atividades em caráter transnacional, em sentido hegemônico capitalista, diferente do modelo democrático sistematizado por Cruz e Bodnar.

A floresta amazônica é composta por uma diversidade de habitats, paisagens e fisionomias. Soma-se a esse cenário a grande complexidade hídrica que caracteriza e alimenta sua heterogeneidade. Índios, quilombolas, extrativistas, seringueiros, castanheiros, quebradeiras de coco, ribeirinhos e agricultores familiares fazem parte da população amazônica, habitam terras formalmente reconhecidas como terras indígenas, reservas extrativistas, reservas de desenvolvimento sustentável, terras quilombolas, projetos de assentamento extrativistas, terras devolutas e unidades de conservação.

Trata-se de um desafio à coordenação para manutenção dos diferentes habitats adicionada aos grandes interesses que permeiam ações de desenvolvimento regional, econômico ou sustentável para o espaço amazônico, considerando as possíveis formas de convivências e coexistência com a diversidade existente.

Em relação à complexidade da transnacionalidade, é necessário estudar a proteção jurídica dos conhecimentos tradicionais associados (CTAs) à biodiversidade amazônica. Urge substituir o sistema de patentes e a garantia dos direitos de autor, inadequados para proteger as comunidades tradicionais. A conservação da biodiversidade amazônica e dos conhecimentos tradicionais (CTs) exige, necessariamente, o compromisso e a organização da Bolívia, do Brasil, da Colômbia, do Equador, das Guianas, do Peru, do Suriname e da Venezuela.

Em razão da biopirataria e o constante desmatamento da floresta amazônica, que acarreta a perda dos CTs, é importante a integração entre os países amazônicos, preconizada pela Organização do Tratado de Cooperação Amazônica (OTCA) e a integração entre os Estados em vários blocos regionais existentes ao longo do sistema internacional. Destacam as questões culturais, políticas, jurídicas e de soberania.

Durante o século XX, as fronteiras nacionais se multiplicaram e se articulou uma nova forma de organização interestatal. A integração dos países amazônicos torna-se de fundamental importância para o enfrentamento das consequências da globalização. Há uma pauta axiológica comum que preconiza sobremaneira a citada integração, qual seja, a conservação da floresta amazônica, compartilhada pelos oito países (Brasil, Venezuela, Guia- 
na, Colômbia, Equador, Peru, Bolívia e Suriname) integrantes do Tratado de Cooperação Amazônico (TCA).

Ampliar essa participação no sistema internacional, não só no âmbito econômico, mas também político, cultural e social, faz parte do objetivo central dos países envolvidos nesse processo de integração regional sul-americano. Há interesse e necessidade de integrar os países amazônicos. Considerando que a Amazônia é constituída como fronteira do capital natural em nível global, Becker identifica dois projetos: “o primeiro é um projeto internacional para a Amazônia, e o segundo é o da integração da Amazônia, sul-americana, continental" (BECKER, 2006, p. 74).

O primeiro projeto, principalmente na década de 1980 e 1990, "gerou sugestões mundiais pela soberania compartilhada e o poder de gerenciar a Amazônia, que abalou até o Direito Internacional" (BECKER, 2006, p. 77). O segundo projeto, o da integração da Amazônia sul-americana, trata-se de uma "nova escala para pensar e agir na Amazônia" (BECKER, 2006, p. 78-79).

A importância dessa integração encontra-se respaldada em múltiplas razões, entre as quais se destacam: o fortalecimento do MERCOSUL; uma presença coletiva e estratégia comum no cenário internacional; e o estabelecimento de projetos comuns para o aproveitamento da biodiversidade e da água.

Existem óbices à integração dos países amazônicos relacionados à cultura (diferenças linguísticas e de tipos de colonialismos), à política (atritos entre os Estados), ao direito (diferenças legislativas) e à soberania (interesses exclusivamente nacionalistas e reforço das fronteiras nacionais).

[...] os movimentos contestatórios na Bolívia, a violência permanente na Colômbia e as tentativas de alterar as regras do jogo de uma democracia formal representativa no Peru e na Venezuela, os movimentos sociais no Brasil e os protestos contra a política fiscal do governo na Argentina, o subcontinente está em efervescência e em Milza (1980); Wendt (1999); Goldstein e Keohane (2003); Lessa (2002); Suppo e Lessa (2007) busca de saídas para os problemas de suas sociedades (RATTNER, 2002, p. 15).

A ideia de integração ajuda na solução de alguns problemas enfrentados pelos países sul-americanos. Os países que compõem a região amazônica encontram-se livres de instabilidades geradas por conflitos étnicos e disputas fronteiriças, inexiste luta pela hegemonia da região. Existe uma postura historicamente pacífica entre esses países.

Um dos maiores óbices para a efetivação do processo integracionista diz respeito à eliminação de diferenças legislativas. O Tratado de Assunção preceitua a harmonização do direito como meta a ser atingida. Um dos pressupostos para o sucesso na consolidação e aperfeiçoamento do MERCOSUL é que essas diferenças sejam minimizadas, principalmente as normas que regem a atuação empresarial em cada Estado-membro, com significativo impacto nos seus custos de produção.

A soberania é o óbice mais evidente à integração entre os países amazônicos. Em relação ao MERCOSUL, as Constituições do Paraguai e Argentina admitem a ordem jurídica supranacional. 
O inciso IV, do artigo $4^{\circ}$. da Constituição da República Federativa do Brasil (CRFB) determina que nas suas relações internacionais o Brasil se rege pelo "princípio da não intervenção". O parágrafo único do mesmo dispositivo estabelece que o Brasil "buscará a integração econômica, política, social e cultural dos povos da América Latina, visando à formação de uma comunidade latino-americana de nações".

$\mathrm{O} \S 2^{\circ}$. do artigo $5^{\circ}$. da CRFB determina que os direitos e garantias expressos na Constituição "não excluem outros decorrentes do regime e dos princípios por ela adotados, ou dos tratados internacionais em que a República Federativa do Brasil seja parte".

Embora existam os obstáculos citados, alguns antecedentes podem servir de plataforma para a almejada integração dos países membros do TCA, a saber: os tratados internacionais levados a efeito pelo MERCOSUL e TCA, a criação da Rede latino-americana de Ministério Público Ambiental e a integração estabelecida entre os povos amazônicos.

Ancorado na pressão de uso e impacto que as populações exercem sobre o ambiente amazônico e suas relações com o modo como ocupam, exploram e concebem sua relação com a natureza, Lima e Pozzobon desenvolveram um modelo socioambiental de ocupação humana da Amazônia e um modelo das demandas socioambientais para resolver o aumento do grau de sustentabilidade das categorias analisadas.

O elemento mais importante em uma estratégia de desenvolvimento sustentável na Amazônia está na aplicação sistemática da ciência e da tecnologia para o uso e a exploração sustentável de sua biodiversidade, o que supõe atividades empresariais e políticas públicas bem diferentes das que predominam nos dias de hoje (LIMA e POZZOBON, 2005, p. 49).

Os povos tradicionais dos países que compõem a região amazônica desconhecem fronteiras, produzem CTAs à biodiversidade por meio de constante compartilhamento de saberes. Estimulados pela tradição oral da difusão do conhecimento tradicional (CT), pela troca de experiências sobre um mesmo bioma e pela lógica coletiva de intercâmbio de saberes, os diferentes povos da região amazônica geram CTA assemelhado.

As particularidades da Amazônia reclamam por um sistema normativo relacionado à realidade dos povos amazônicos, e, assim, tornar efetiva a proteção ao CT gerado nessa região transnacional. $\mathrm{O}$ Direito Transnacional relacionado à questão ambiental agrega a mesma lógica do Estado Constitucional Moderno, formado por normas jurídicas inter-relacionadas que constituem um regime jurídico.

O Direito Transnacional transpassa vários Estados nacionais, com capacidade de aplicação coercitiva por estrutura organizativa transnacional, com características próprias, derivadas da concepção do Estado Transnacional, com organização para atuar em espaço de governança regulatória e intervenção. A criação de espaços jurídicos transnacionais, com poderes coercitivos, formulados democraticamente, proporcionará a efetividade da proteção ambiental amazônica e, por conseguinte, a proteção aos povos e seus CTs. 


\title{
3 A PROTEÇÃo JURÍDICA DOS CONHECIMENTOS TRADICIONAIS NA BOLÍVIA, na Colômbia, no Equador, nas Guianas, no Peru, no Suriname e na VENEZUELA
}

As Constituições dos países sul-americanos são modernos e atuais documentos nos quais já estão previstas a proteção dos direitos fundamentais. "As Constituições da Bolívia de 2009, do Equador de 2008, da Venezuela de 1999, do Brasil de 1988, da Colômbia de 1991" (AGUIAR DE LUQUE e LOPEZ GUERRA, 2009, p. 125) estabelecem demandas transnacionais e preveem formar uma comunidade latino-americana de nações.

Em 2008, a Constituição da Bolívia e, em 2009, a Constituição do Equador proclamaram que os povos indígenas e os defensores do meio ambiente são filhos e filhas da Mãe Terra (Madre Tierra ou Pachamama), ou seja, "ser vivo do universo que concentra energia e vida e que ela fornece sombra e vida a todos os seres vivos sem pedir nada em troca" (MORAES e MARQUES JÚNIOR, 2011, p. 249-250).

Garcia, Marques Júnior e Pilau Sobrinho (2014, p. 964) explicam que o novo constitucionalismo democrático latino-americano surgiu devido à necessidade de buscar soluções originais de problemas locais comuns e regionais dos povos americanos. Urge a integração regional para construir uma nova cidadania sul-americana para o futuro da humanidade, o desenvolvimento dos povos e a proteção ambiental.

Apenas a Constituição da Bolívia de 1967 se refere indiretamente à questão ambiental, porque reflete o pensamento da época. Trata da proteção da vida e da saúde, ao dispor que os bens naturais são da coletividade no artigo $7^{\circ}$., alíneas "a", "d", "h", "i", alterados em 2002. Na concepção de Gutiérrez:

\begin{abstract}
La nueva Constitución Política del Estado boliviano, promulgada en febrero del año 2009, ha incorporado dentro del Título de los Derechos Fundamentales y Garantías como un derecho de orden social y económico el correspondiente al medio ambiente. Portanto, conforme o Art. 33: 'Las personas tienen derecho a um medio ambiente saludable, protegido y equilibrado. El ejercicio de este derecho debe permitir a los individuos y colectividades de las presentes y futuras generaciones, además de otros seres vivos, desarrollarse de manera normal y permanente' (GUTIÉRREZ, 2009, p. 52-57).
\end{abstract}

Em relação à tutela efetiva do direito, a Constituição Política do Estado abre a possibilidade de interposição de ações de defesa por meio dos recursos que o próprio texto constitucional oferece. O artigo 34 da Constituição da Bolívia autoriza a qualquer pessoa, individualmente ou em representação de uma comunidade, ter o direito de exercer ações judiciais em defesa do direito ao meio ambiente, sem prejuízo da obrigação das instituições públicas de defesa do meio ambiente.

Em 1991, o artigo $8^{\circ}$. da Constituição da Colômbia, alterada em 2005, se referiu à obrigação do Estado e do povo de proteger as riquezas culturais e naturais. O artigo 49 tratou da saúde e do saneamento ambiental. O artigo 78 inaugurou o Capítulo III que tratou, especificamente, do meio ambiente e dos direitos coletivos. 
En Colombia el derecho ambiental ha venido tomando fuerza a partir de la expedición de la Constitución de 1991 y la implementación que de ella se há hecho principalmente a partir de las acciones populares y de tutela.

La proliferación de normas existentes en el país desde 1959 o antes, no habían sido desarrolladas jurídicamente, sino más bien con un marcado sesgo técnico. Actualmente, aun cuando controvertibles algunas posiciones de las altas cortes, es indudable la necesidad de reconocer el avance en matéria de desarrollo de un marco jurídico de la implementación e interpretación de las normas ambientales (GOMEZ, 2009, p. 214).

A Constituição da Colômbia trata da responsabilidade civil por danos ambientais. $\mathrm{Na}$ Constituição da Venezuela a responsabilidade é subjetiva, com inversão do ônus da prova. $\mathrm{Na}$ Constituição do Peru a responsabilidade é subjetiva, com solidariedade dos profissionais que assinaram o Estudo de Impacto Ambiental, com o destaque da independência da responsabilidade penal e civil da pessoa jurídica.

A Bolívia e a Colômbia publicaram a Lei de Política Ambiental, porém não há referência expressa à responsabilidade civil ambiental. A partir de 1976, surgiu a preocupação com a questão ambiental na Venezuela, com a promulgação da Lei Orgânica do Ambiente. Em 1977, foi criado o Ministério do Ambiente e dos Recursos Naturais Renováveis. Em 2005, na Guiana Francesa, a Declaração de Limoges objetivou desenvolver, na área jurídica, políticas públicas do meio ambiente e desenvolvimento sustentável.

A Constituição da Bolívia de 1967, modificada em 2002, não dispõe expressamente sobre o meio ambiente. Os artigos $7^{\circ}$. e 19 estabelecem uma proteção indireta ao meio ambiente, por meio da tutela de Direitos Fundamentais, como o direito à vida e à saúde, e a tutela de bens naturais da coletividade.

$\mathrm{O}$ embate entre meio ambiente e as demandas da sociedade tecnológica, somadas à grande exploração de recursos naturais, geram tendências alarmantes, como a perda da biodiversidade e dos CTAs dos povos tradicionais.

A Bolívia detém significativo patrimônio genético, originário das regiões amazônica e andina, com caráter estratégico internacional, pela importância econômica e social que desempenham. Aliada à diversidade de espécies, há a diversidade étnica boliviana.

As comunidades locais bolivianas são compostas, principalmente, pela população majoritária de índios e camponeses. Esses povos aproveitam, de forma sustentável, uma enorme diversidade biológica. Podem ser regidos total ou parcialmente por seus próprios costumes e tradições ou por uma legislação especial que lhes permita manter suas próprias instituições sociais, econômicas, culturais e políticas. Segundo a Comunidad Andina de Naciones (2001), manejam de forma sustentável os recursos naturais localizados em seus territórios. Considerando que os CTAs à biodiversidade

(...) vão desde técnicas de manejo de recursos naturais, métodos de caça e pesca, conhecimentos sobre os diversos ecossistemas e sobre propriedades farmacêuticas, alimentícias e agrícolas de espécies e as próprias categorizações e classificações de espécies de flora e fauna utilizadas pelas populações tradicionais. (...) As técnicas de manejo tradicional incluem domesticação e manipulação de espécies de fauna e flora, vinculadas às atividades relacionadas à agricultura itinerante, à introdução de espécies de árvores frutíferas nas roças de mandioca, 
à caça de subsistência, às técnicas de pesca, à construção de pesqueiros e à utilização de calendários complexos de atividades que reúnem coleta e cultivo (SANTILLI, 2003, p. 83-84).

O crescimento demográfico boliviano, somado a práticas de manejo pouco sustentáveis dos recursos disponíveis, tem levado a uma crescente divisão das terras das áreas andinas rurais e das áreas tradicionalmente ocupadas, impelindo a uma intensificação do aproveitamento dos recursos naturais disponíveis nessas regiões. A consequência é a deterioração do potencial produtivo das terras, do meio ambiente e a destruição da vida silvestre.

Está ocorrendo o aumento do processo de migração dos povos da região andina para as cidades. A expansão da malha viária nos países-membros da Comunidade Andina possibilitou a orientação de fluxos internos de migração até as cidades. Esses processos reduziram os recursos tradicionalmente utilizados pelos povos indígenas e locais, bem como, a perda total do habitat de alguns povos.

O crescimento demográfico dos povos amazônicos acarretou uma maior expansão das atividades econômicas e empresariais, levando à intensa exploração da área, afetando os recursos naturais das áreas indígenas.

La realidad actual es que la población indígena sobrevive al margen del desarrollo en una sociedad que no promueve políticas adecuadas para los grupos étnicos. En los últimos 15 años han desaparecido al menos cuatro grupos indígenas que vivian en las tierras bajas (los simonianos, los toromonas, los bororos y los joras). Además, otros grupos, como los chimanes, los mojos y los movimas están enfrentando actualmente las amenazas de la colonización por parte de emigrantes de zonas andinas (YASAREKOMO, s.d., p. 3).

A perda crescente das florestas reduziu a caça, prejudicou a sobrevivência de alguns povos, impossibilitou a satisfação das necessidades básicas das populações, que precisaram recorrer a fontes complementares de sobrevivência, como o trabalho na agroindústria ou a venda de madeira. Os CTs também foram afetados, eis que muitas práticas foram substituídas ou abandonadas variedades e produtos tradicionais, sendo adotados os mais aceitos no mercado e valorizados pela vida moderna, como o aspecto exterior, que vêm se impondo à preferência do consumo.

A educação bilíngue nativo-espanhola é reivindicação compartilhada por todos os povos indígenas da Comunidade Andina (CAN), uma organização regional com personalidade jurídica internacional, constituída pela Bolívia, Equador, Peru e Colômbia. É aceita pelo governo boliviano como política oficial e reconhecida como direito. Porém, ainda não se articulou efetivamente com a questão da transmissão dos conhecimentos e práticas tradicionais, seus atributos e o manejo sustentável.

Os mecanismos de transmissão dos CTAs à biodiversidade já não operam adequadamente, porque o CT que hoje tem a maior parte dos jovens indígenas é muito menor que o de seus pais e avós. O Estado realiza somente a assistência técnica e transferência tecnológica, orientada, principalmente, à introdução de variedades de sementes melhoradas cotizadas no mercado e de agroquímicos, sem nenhuma relação com os CTAs. 
Atualmente, tem-se produzido um considerável avanço no movimento indígena da Bolívia. Muitas de suas reivindicações estão sendo assumidas como políticas governamentais.

Na Bolívia, inexistem mecanismos adequados para obter o direito e o controle efetivo sobre a terra e o território dos povos tradicionais, que representa a identidade desses povos. Soma-se a questão ainda não resolvida da propriedade intelectual sobre os CTs.

As empresas bolivianas e a ciência ocidental têm demonstrado interesse nos CTs, uma fonte valiosa de conhecimento. Descumprem as obrigações inerentes ao uso e ao consentimento. Contribuem na sua perda, por meio da destruição do ambiente e dos valores culturais dos povos tradicionais. Na Bolívia, os CTs são considerados informações de domínio público, às quais todos podem utilizar de forma livre, conforme determinam as leis referentes à PI. Porém, os CTs têm sido apropriados por pesquisadores e empresas comerciais sobre os direitos de PI, sem nenhuma recompensa ou benefício aos seus criadores ou possuidores.

Em 1994, a Bolívia se tornou signatária da CDB e passou a incorporar os seus princípios à legislação interna, para garantir o gerenciamento de seus recursos genéticos e os direitos dos povos tradicionais bolivianos. Inexiste uma norma nacional boliviana específica relativa à conservação da biodiversidade. A CDB tem objetivos confirmados nos artigos 136 e 170 da Constituição Política do Estado e, principalmente, na Ley del Medio Ambiente, Lei n. 1.333, de 1992, que estabeleceu o marco geral para a questão. A referida lei determina ao Estado a promoção da pesquisa e do desenvolvimento científico e tecnológico referente ao meio ambiente, à recuperação, uso e melhoramento das tecnologias tradicionais e o controle sobre a introdução e geração de tecnologias que ponham em risco o meio ambiente.

Pereyra (2000, p. 2) explica que os artigos $1^{\circ}$. ao 171 da Constituição da Bolívia de 1967, alterada em 1995, reformada e promulgada em 2002, dispõem sobre a natureza multiétnica e pluricultural da Bolívia, bem como, o reconhecimento da identidade, valores, costumes e instituições dos povos indígenas e originários, havendo, pela primeira vez na história da Bolívia, o reconhecimento da existência de diversas culturas e cosmovisões, no marco do acordado no Convênio 169 da OIT.

A Constituição da Colômbia de 1991, modificada em 2005, dispõe expressamente sobre meio ambiente nos artigos $8^{\circ} ., 49,78,79,80,82,88$ a 95, 339 e prevê responsabilidade civil objetiva. A Constituição colombiana é uma das poucas das Américas que expressamente reconhece o caráter multiétnico e pluricultural da nação e, como consequência, as formas próprias de autoridade e de jurisdição indígena dentro dos territórios indígenas.

Em 1995, na Colômbia foi elaborado um projeto de lei que visava regular a proteção, conservação e utilização da diversidade biológica e dos recursos genéticos. O Grupo ad hoc de biodiversidade da Colômbia foi o responsável pela preparação do referido projeto de lei, que já trazia em seu texto vários artigos sobre o CT e direitos intelectuais coletivos. O referido Grupo inclui o Instituto Latinoamericano de Servicios Legales Alternativos (Ilsa), Grupo Semillas, o Instituto de Gestión Ambiental (Igea), e o projeto de implementação da Convenção da Diversidade Biológica do World Wildlife Fund (WWF).

O citado projeto de lei expressamente excluiu do âmbito de sua aplicação os seres humanos, os seus recursos genéticos, as suas células e a troca entre as comunidades locais de 
recursos biológicos, que contenham recursos genéticos ou componentes intangíveis associados a eles, com a finalidade de atender às necessidades dessas comunidades resultantes de suas práticas habituais.

O governo colombiano reconhece e se compromete a promover e defender os direitos dos povos tradicionais, incentivar a prática de suas tradições e costumes, compensar os povos por seu papel de conservar e desenvolver materiais genéticos de grande utilidade para a nação. Reconhece e se compromete a defender os direitos desses povos de proteger seu CT, seja mediante direitos de PI ou outros mecanismos. A Colômbia desenvolve um avançado processo de consulta a comunidades tradicionais e indígenas em relação a leis e projetos que interferem em suas vidas. Trata-se de um mecanismo previsto na Convenção n. 169 da Organização Internacional do Trabalho (OIT) de 1989.

A Constituição do Equador de 1998 dispõe, expressamente, sobre o meio ambiente no inciso III, do artigo $3^{\circ}$. e não há previsão de responsabilidade objetiva. A nova Constituição equatoriana, aprovada em 28 de setembro de 2008, é a primeira no mundo a reconhecer legalmente os direitos da natureza, ou dos ecossistemas.

A maior contribuição da nova Constituição equatoriana é a visão biocêntrica. Introduz o conceito de direitos da natureza e invoca a sabedoria de todas as culturas que nos enriquecem como sociedade. Dispõe no artigo 71 que a natureza, ou Pacha Mama, onde se reproduz e se realiza a vida, tem direito a que se respeite integralmente a sua existência e a manutenção e regeneração de seus ciclos vitais, estrutura, funções e processos evolutivos.

A referida Constituição determina que toda pessoa, comunidade, povoado ou nacionalidade poderá exigir da autoridade pública o cumprimento dos direitos da natureza. Para aplicar e interpretar esses direitos, é necessário observar os princípios estabelecidos na Constituição no que for pertinente. Estabelece que o Estado incentivará as pessoas naturais e jurídicas e os entes coletivos para que protejam a natureza e promovam o respeito a todos os elementos que formam um ecossistema.

Quanto à proteção jurídica dos CTs no Equador, Wanndscheer (2009, p. 158) explica que o Estado é reconhecido como titular de todo CT produzido por sua população. No Equador, a produção intelectual (PI) é identificada pelo regime de PI, como um fato eminentemente individual, isto quando não se refere às pessoas jurídicas. No âmbito de proteção da PI, é o mesmo que regula os institutos da propriedade industrial, que tradicionalmente segue rito próprio de identificação e especificação do objeto da proteção. Trata-se de um entrave à necessária abrangência da proteção esperada para a biodiversidade, reivindicada pelos povos tradicionais.

Adelaide-Merland (2002, p. 10) explica que, desde o século XVIII, nas Guianas existem as redes de intercâmbio, entre as quais se destaca a parceria interpessoal de troca (pawana e panary), cuja lógica é compartilhada em toda a região. A Constituição da Guiana de 1980, modificada em 1996, dispõe expressamente sobre meio ambiente e nos artigos 25 e 86 o caráter transgeracional do meio ambiente. Porém, na Guiana como na Guiana Francesa ainda não há legislação específica relativa à proteção jurídica dos CTAs à biodiversidade.

A Constituição do Peru de 1993, modificada em 2005, dispõe expressamente sobre meio ambiente. Nos artigos 66 e 69, menciona o uso sustentável dos recursos naturais e o desenvolvimento sustentável da Amazônia. Porém, não há previsão de responsabilidade 
objetiva. Em 2002, o tema da proteção jurídica dos CTs no Peru foi abordado pela Propuesta de Régimen de Protécion de los Conocimientos Colectivos de los Pueblos y Comunidades Indigenas vinculados a los recursos Biológicos.

O projeto de lei peruana regula o acesso aos recursos genéticos e resguarda os CTs indígenas associados à biodiversidade. Foi elaborado por um grupo formado por representantes de comunidades indígenas, ONG's e funcionários dos Ministérios da Agricultura, Saúde e Indústria e do Instituto Nacional de Defesa da Propriedade Intelectual. O artigo 63 do Decreto Legislativo n. 823 estabelece que o Estado tem o dever de formular normatização especial para proteger e registrar os CTs de comunidades indígenas e rurais.

O Peru foi o primeiro país a aprovar uma lei interna estabelecendo um regime de proteção dos conhecimentos coletivos dos povos indígenas vinculados aos recursos biológicos.

A Constituição do Suriname de 1987 dispõe expressamente sobre o meio ambiente, menciona equilíbrio ecológico e natural, mas vincula os recursos naturais ao desenvolvimento. A Constituição do Suriname trata o meio ambiente como norma constitucional nas alíneas "a", "g" do artigo $6^{\circ}$. e no artigo 41 condiciona os recursos naturais. Porém, não há previsão de responsabilidade objetiva. Quanto à proteção jurídica dos CTAs à biodiversidade, não há legislação específica relativa ao tema no Suriname.

A Constituição da Venezuela de 1999, em vigor a partir de março de 2000, dispõe expressamente sobre o meio ambiente, a tutela de patrimônio genético e prevê o estudo de impacto ambiental nos artigos 127, 128 e 129. O artigo 10 trata da educação ambiental. Entretanto, não há previsão de responsabilidade objetiva.

A referida Constituição reconhece o caráter multiétnico, pluricultural e multilíngue da Venezuela. Garante e protege a propriedade intelectual coletiva dos conhecimentos, tecnologias e inovações dos povos indígenas. O artigo 124 da Constituição venezuelana proíbe o registro de patentes sobre esses recursos e conhecimentos ancestrais.

A Lei da Biodiversidade da Venezuela garante os direitos dos povos e comunidades indígenas e locais. A referida lei estabelece que os direitos de caráter coletivo serão considerados como direitos adquiridos. $\mathrm{O}$ artigo 82 da referida lei dispõe que não se reconhecerá direitos de PI sobre amostras coletadas ou parte delas, quando as mesmas tenham sido adquiridas de forma ilegal, ou que empreguem o conhecimento coletivo de povos e comunidades indígenas ou locais.

\section{CONSIDERAÇões FINAIS}

Em função da problemática e da hipótese, o trabalho em testilha não propôs a articulação entre os ordenamentos jurídicos internos e o tratamento jurídico transnacional proposto (tratado ou a criação de um organismo multilateral). O objetivo geral do trabalho consiste em analisar a proteção jurídica dos conhecimentos tradicionais associados à biodiversidade nos países que integram a região amazônica, considerando a imprescindível inter-relação dos conhecimentos tradicionais dos povos da Amazônia com a conservação ambiental.

O trabalho em testilha estudou a transnacionalidade e a proteção jurídica dos conhecimentos tradicionais na Bolívia, na Colômbia, no Equador, nas Guianas, no Peru, no Surina- 
me e na Venezuela. Pela amplitude do tema e a necessidade de melhorar a proteção jurídica desses importantes conhecimentos, requereu um esquema conceitual que the conferiu um instrumental teórico suficientemente articulado para a sua problemática. Foi utilizado o método indutivo e nas diversas fases da pesquisa foram acionadas as técnicas do referente, da categoria, do conceito operacional, da pesquisa bibliográfica e do fichamento.

$\mathrm{O}$ trabalho evidenciou a necessidade de um tratamento transnacional aos conhecimentos tradicionais associados à biodiversidade nos países que integram a região amazônica. $\mathrm{O}$ aludido problema concentrou seus esforços na busca de substituir o sistema de patentes, bem como, o sistema de garantia dos direitos de autor, inadequados para proteger as comunidades tradicionais. Tendo em consideração esse fim, percorreu-se, do ponto de vista do marco de referência, a bibliografia de relevância já tornada pública em relação ao tema de estudo.

O equacionamento do problema suscitou na hipótese de que a floresta amazônica está inserida além do Brasil, em territórios de outros países sul-americanos como Suriname, Venezuela, Guianas, Colômbia, Equador, Peru e Bolívia, portanto, sua conservação exige, necessariamente, o compromisso e a organização de todos esses países.

O presente trabalho atingiu o objetivo geral que foi analisar a proteção jurídica dos conhecimentos tradicionais associados à biodiversidade amazônica, considerando a imprescindível inter-relação dos conhecimentos tradicionais dos povos da Amazônia com a conservação ambiental.

O trabalho estudou o conceito, as características e o paradigma da transnacionalidade, elucidou o conceito de conhecimentos tradicionais associados à biodiversidade amazônica e os povos tradicionais. Analisou a legislação aplicada aos conhecimentos tradicionais na Bolívia, na Colômbia, no Equador, nas Guianas, no Peru, no Suriname e na Venezuela. Ressaltou que o sistema de patentes e o sistema de garantia dos direitos de autor são inadequados para proteger as comunidades tradicionais, imbricando-o metodologicamente por estreita pertinência temática e lógica ao objeto do trabalho.

Dessa forma, o trabalho cumpriu os objetivos específicos propostos e alcançou os achados pretendidos, a saber: estudou o conceito, o paradigma, as características e noções gerais da transnacionalidade; verificou no ordenamento vigente o arcabouço jurídico aplicado aos conhecimentos tradicionais dos povos da Amazônia na Bolívia, na Colômbia, no Equador, nas Guianas, no Peru, no Suriname e na Venezuela, países que integram a região amazônica; enfatizou a limitada proteção que oferecem os direitos nacionais e a tutela internacional em vigor relacionada aos conhecimentos tradicionais associados à biodiversidade amazônica, considerando sua imprescindível inter-relação com a sustentabilidade.

\section{REFERÊNCIAS}

ADELAIDE-MERLAND, Jacques. Historie contemporaine de la Caribe et des Guyanes: de 1945 à nos jours. Paris: Éditions Karthala, 2002.

AGUIAR DE LUQUE, Luis; LOPEZ GUERRA, Luis. Las Constituciones de Iberoamérica, 2. ed. Madrid: Centro de Estudios Políticos e Constitucionales, 2009. 
BECK, Ulrich. La sociedad del riesgo global. Madrid: Siglo XXI de Espanha Editores, 2002.

BECKER, Bertha Koiffmann. Amazônia: geopolítica na virada do III milênio. Rio de Janeiro: Garamond, 2006.

COMUNIDAD ANDINA DE NACIONES. Estrategia Regional de Biodiversidad. Protección, Recuperación y Difusión de conocimientos y Prácticas Tradicionales. Bolívia, 2001. Disponível em: http://www.comunidadandina.org. Acesso em: 24 jul. 2019.

CRUZ, Paulo Márcio; BODNAR, Zenildo. A transnacionalidade e a emergência do estado e do direito transnacionais. In: Direito e transnacionalidade. CRUZ, Paulo Márcio; STELZER, Joana (Orgs.). Curitiba: Juruá, 2009.

FERRAJOLI, Luigi. Derechos y garantias: la ley del más débil. Tradução de Andréa Greppi. Madrid: Alianza, 1999.

FERRER, Gabriel Real. La Construcción del Derecho Ambiental. Revista Arazandi de Derecho Ambiental, Pamplona, Espanha, n. 1, p. 73-93, 2002.

GARCIA, Marcos Leite; MARQUES JÚNIOR, William Paiva; PILAU SOBRINHO, Liton Lanes. Aportes do novo constitucionalismo democrático latino-americano e da UNASUL para os direitos fundamentais: os direitos ambientais como demandas transnacionais e o tratamento prioritário da sustentabilidade. Revista Eletrônica Novos Estudos Jurídicos, v. 19, n. 3, p. 959-993, set./dez., 2014.

GOMEZ, Luís Fernando Macias. Derecho Ambiental colombiano. In: STEIGLEDER, Annelise Monteiro; LOUBET, Luciano Furtado (Orgs.). O Direito Ambiental na América Latina e a atuação do Ministério Público. Tomo I - América do Sul. Belo Horizonte: Rede Latino-Americana de Ministério Público Ambiental e Associação Brasileira do Ministério Público - ABRAMPA, 2009.

GUTIÉRREZ, Diego. O Derecho Ambiental en Bolívia. In: STEIGLEDER, Annelise Monteiro; LOUBET, Luciano Furtado (orgs.). O Direito Ambiental na América Latina e a atuação do Ministério Público. Tomo I - América do Sul. Belo Horizonte: Rede Latino-Americana de Ministério Público Ambiental e Associação Brasileira do Ministério Público - ABRAMPA, 2009.

JESSUP, Philip Caryl. The Concept of Transnational Law: An Introduction, 3 COLUM. J. OF TRANSNAT'L L. 1963.

. Transnational Law. New Haven: Yale University Press, 1956. 
KHUN, Thomas S. A estrutura das revoluções científicas, 5. ed. São Paulo: Perspectiva, 2000.

KOH, Harold Hongju. Transnational Legal Process. Yale Law School Legal Scholarship Repository, v. 75, n. 181, Nebraska Law Review, 1996. Disponível em: http:/digitalcom mons.law.yale.edu/fss_papers/2096/. Acesso em: 17 jul. 2019.

LIMA, Deborah; POZZOBON, Jorge. Amazônia socioambiental. Sustentabilidade ecológica e diversidade social, v. 19, n. 54. São Paulo, mai./ago., 2005. Disponível em:http:// www. scielo.br/scielo.php?pid= S0103-142005000200004\&script=sci_arttext. Acesso em: 10 jul. 2019.

MORAES, Germana de Oliveira; MARQUES JÚNIOR, William Paiva. O desafio da UNASUL de aproveitamento sustentável dos recursos energéticos e o novo paradigma ambiental. In: CADEMARTORI, Daniela; CADEMARTORI, Sérgio; MORAES, Germana de Oliveira; COELHO, Raquel. A construção jurídica da UNASUL. Florianópolis-SC. Fundação José Arthur Boiteux/UFSC, 2011.

PEREYRA, Javier Ernesto Muñoz. Los derechos indígenas y los derechos de Propiedad Intelectual. Bolívia: UNCTAD, 2000. Disponível em: http://www.comunidadandina.org/ desarrollo/ tradicionales.pdf. Acesso em: 22 jul. 2019.

RATTNER, Henrique. O futuro incerto dos países sul-americanos. São Paulo: Universidade de São Paulo, 2002.

SANTILLI, Juliana. Biodiversidade e conhecimentos tradicionais associados: novos avanços e impasses na criação de regimes legais de proteção. Revista de Direito Ambiental, São Paulo, ano 8, n. 29, p. 83-102, jan./mar., 2003.

SILVA, José Germán Burgos. El derecho internacional em el contexto de la globalización: conflictos y transformaciones. Estudios de Derecho. v. LXVIII, n. 152, Facultad de Derecho y Ciencias Políticas, Universidad de Antioquia, Medellín, Colombia, 2011.

WANNDSCHEER, Clarissa Bueno. Patentes \& Conhecimento Tradicional. Uma abordagem socioambiental da proteção jurídica do Conhecimento Tradicional. Curitiba: Juruá, 2009.

YASAREKOMO. Una experiencia de comunicación indígena en Bolivia. s.1: FAO, s.d. Disponível em: http:/www.fao.org//docrep/006/y53311s/y5311s04.htm. Acesso em: 23 jul. 2019.

Ana Carolina Couto Matheus

Doutora em Ciência Jurídica pela UNIVALI-SC. Mestre em Direito pela UNIPAR-PR. Es- 
pecialista em Direito Tributário pela UnP-RN. Professora Adjunta III do CCJSA da UFAC-AC. Coordenadora do Núcleo de Prática Jurídica e Estágios. Professora da Pós-Graduação. Advogada.

E-mail: carolcoutomatheus@hotmail.com.

Submetido em: 25-7-2019

Aceito em: 3-9-2020 